\title{
Studies on crystal structure, magnetic and conductivity prop- erties of the titanium oxycarbide solid solution $\left(\mathrm{TiO}_{1-\mathrm{x}} \mathrm{C}_{\mathrm{x}}\right)$
}

\author{
David N. Miller, Abdul K. Azad, Heloise Delpouve, Lucille Quazuguel, Jun Zhou, Amit Sinha, Philip \\ Wormald and John T.S. Irvine \\ The School of Chemistry, University of St Andrews, St Andrews, KY16 9ST, UK.
}

\begin{abstract}
Titanium oxides and carbides are often considered as electrode materials in energy conversion and storage devices due to their high potential conductivity and good stability. Titanium monoxide and titanium carbide have structures that can both be described as rocksalt with the same cubic close packed titanium sublattice with oxygen and carbon respectively occupying the octahedral interstices; however the oxide is characterised by extensive defects on both sublattices whilst the carbide is stoichiometric and might be considered as an interstitial metal. Despite the anticipated very different natures of the oxide and carbide sublattices, these two phases actually form a complete solid solution. In the present investigation, we carefully characterise this titanium oxycarbide solid solution, reporting on crystal structure, magnetic and electronic conduction properties. Titanium oxycarbide powders $\left(\mathrm{TiO}_{1-\mathrm{x}} \mathrm{C}_{\mathrm{x}}\right.$ with $\left.\mathrm{x}=0 \leq \mathrm{x} \leq 1\right)$ have been prepared by solid state reaction of $\mathrm{TiO}$ and $\mathrm{TiC}$ powder under controlled environments at elevated temperatures. X-ray diffraction and pycnometric density measurements illustrate the gradual transition of crystal structure of titanium oxycarbides from vacancy containing rock-salt structure of TiO to the fully occupied $\mathrm{TiC}$ with increase in carbon content in the oxycarbide lattice. The variation of lattice parameter of oxycarbide crystal as a function of carbon content has been found to be non-linear which can be attributed to variations in the level of vacancies present in metal as well as non-metal sub-lattices. The existence of short-range ordering of anion vacancies in oxycarbide with a nominal composition of
\end{abstract}


$\mathrm{TiO}_{0.5} \mathrm{C}_{0.5}$ where half of oxygen of $\mathrm{TiO}$ is replaced by carbon has been confirmed by selected-area electron diffraction studies. Low temperature magnetic and conductivity measurements confirm that all oxycarbide compositions are Pauli paramagnetic and good metallic conductors.

KEYWORDS Titanium monoxide, titanium carbide, titanium oxycarbide.

\section{Introduction}

Whilst titanium oxycarbides are known, especially in some engineering applications, the extent, chemistry and physical properties of the solid solution have not been systematically explored. Titanium oxycarbide has been considered to be a solid solution of titanium monoxide ( $\mathrm{TiO})$ and titanium carbide ( $\mathrm{TiC})$ with general formula $\mathrm{TiO}_{1-\mathrm{x}} \mathrm{C}_{\mathrm{x}}$ where oxygen and carbon occupy the octahedral interstitial sites in a face centred cubic titanium lattice. ${ }^{1}$ Titanium monoxide, TiO, can exist as a number of phases all closely related to the rock salt structure (space group Fm-3m). Titanium monoxide is one of a small number of compounds that have vacancies on both the the metal and oxygen sublattices. In stoichiometric titanium monoxide $15 \%$ of the titanium and oxygen sites are vacant. ${ }^{2}$ The stable room temperature phase of $\mathrm{TiO}$ is an ordered monoclinic phase (space group B2/b) where metal and oxygen vacancies are located in every third (110) cubic rock salt plane ${ }^{3}$. This monoclinic phase is stable to up to $925^{\circ} \mathrm{C}$. At elevated temperatures a cubic rocksalt phase is stable where the location of the vacant $\mathrm{Ti}$ and $\mathrm{O}$ sites becomes random. ${ }^{4}$ The higher temperature cubic $\mathrm{TiO}$ phase can be non-stoichiometric in the range $\mathrm{TiO}_{0.8}-\mathrm{TiO}_{1.25}$. For compositions between $\mathrm{TiO}$ and $\mathrm{TiO}_{1.25}$ the low temperature and high temperature phases coexist to room temperaure. ${ }^{5}$ Titanium monoxide has been identified as a superconductor below $1 \mathrm{~K}$ and is Pauli paramagnetic and a metallic conductor. ${ }^{6}$ The conduction band of $\mathrm{TiO}$ arises through the overlap of partially filled $\mathrm{t}_{2 \mathrm{~g}}$ orbitals formed by the crystal field splitting of the d-orbitals of neighbouring Ti(II) cations. ${ }^{7}$ Reduced titanium oxides have been widely applied as electrodes in a range of electrochemical applications, especially for the Magneli phases known as Ebonex ${ }^{8}$.

Titanium carbide has recently been successfully utilised as an electrode support in lithium air batteries ${ }^{9}$. Titanium carbide, TiC has a rock salt structure where all the octahedral sites in a titanium lattice are 
occupied by carbon atoms. Similar to other d-block interstitial carbides TiC is a very hard refractory material with a melting point of $3160^{\circ} \mathrm{C}$. Non-stoichiometric titanium carbides, $\mathrm{TiC}_{1-\mathrm{x}}$, can accommodate vacancies on the carbon site up to $50 \% .^{10}$

The solid solution that exists between $\mathrm{TiO}$ and $\mathrm{TiC}$ represents an uninterrupted transition between the predominantly ionic and covalent bonding between titanium and oxygen in $\mathrm{TiO}$ to the metallic refractory nature of $\mathrm{TiC}$ and is accompanied by changes in defect structure and properties.

Early research into the titanium oxycarbide system concentrated on understanding the thermodynamics to facilitate their use in the extractive metallurgy of titanium metal or the commercial production of titanium carbide. ${ }^{11,12}$ More recent studies have concentrated on applications that make use of the properties of titanium oxycarbide itself. Titanium oxycarbides exhibit properties that are characteristic of metallic, ionic and covalent systems. Titanium oxycarbides exhibit high hardness, electrical conductivity and unique optical and catalytic properties. Studies on titanium oxycarbide thin films have shown that the optical, mechanical and electrocatalytic properties can be tailored by altering the processing conditions. 13 Titanium oxycarbide nanotubes and thin films have been utilised as electrically conductive substrates for electrocatalysts. ${ }^{14,15}$ The high hardness of titanium oxycarbide makes it suitable for use in wear resistant coatings. ${ }^{16,17}$

Titanium oxycarbides are most often formed in an inert atmosphere or vacuum from the carbothermal reduction of $\mathrm{TiO}_{2}$ with graphite or hydrocarbons ${ }^{11}$ or by the direct reaction of titanium metal with titanium monoxide, $\mathrm{TiO}$ and titanium carbide, $\mathrm{TiC} .{ }^{1}$ Other studies have demonstrated oxycarbide formation by the direct reduction of $\mathrm{Ti}_{2} \mathrm{O}_{3}$ and $\mathrm{TiO}_{2}$ with $\mathrm{CO},{ }^{18}$ and the oxidation of titanium carbide. ${ }^{19,20}$ Such methods do not easily lend themselve to the synthesis of titanium oxycarbides with specific stoichiometries as there is not full control on all three components. As such very few systematic studies have been carried out on the effect of composition on the structure and properties of titanium oxycarbides. Studies have mainly been limitted to individual compositions as in the case of Jiang et al. $\left(\mathrm{TiO}_{0.5} \mathrm{C}_{0.5}\right)^{1}$, Tashmetov $\left(\mathrm{TiO}_{0.08} \mathrm{C}_{0.545}\right)^{21}$ and Zubkov et al. $\left(\mathrm{TiO}_{0.57} \mathrm{C}_{0.44}\right)^{22}$ or oxycarbides of the general formula $\mathrm{TiO}_{\mathrm{x}} \mathrm{C}_{\mathrm{y}}$ as in the 
case of the thermal expansion coefficient and conductivity study of Ivanov et al. ${ }^{1}$ An exception to this is Zainulin et al. who investigated the mechanism of oxygen incorporation into titanium carbides $\left(\mathrm{TiO}_{\mathrm{x}} \mathrm{C}_{0.5}\right.$, $\mathrm{TiO}_{\mathrm{x}} \mathrm{C}_{0.8}$, etc). ${ }^{20}$ So, despite the research effort that has been committed to understanding the thermodynamics of titanium oxycarbides and the nature of nanostructured titanium oxycarbide thin films, systematic studies on the structure and properties of titanium oxycarbides remain necessary. Here a study of the solid state synthesis and bulk properties of titanium oxycarbides is presented across the entire solid solution that exists between $\mathrm{TiO}$ and $\mathrm{TiC}$.

\section{Materials and Methods}

Compounds in the series $\mathrm{TiO}_{1-\mathrm{x}} \mathrm{C}_{\mathrm{x}}(\mathrm{x}=0,0.1,0.2,0.3,0.33,0.4,0.5,0.6,0.67,0.7,0.8,0.9$ and 1$)$ were prepared by traditional solid-state reaction. Stoichiometric amounts of high-purity ( $>99 \%) \mathrm{TiO}$ and $\mathrm{TiC}$ (Aldrich) were mixed and ground in a Fritsch Pulverisette 7 planetary ball mill. The resulting powders were compacted into pellets of $14 \mathrm{~mm}$ diameter using a uniaxial hydraulic press. The pellets were either fired in a tube furnace in flowing argon at $1400-1450^{\circ} \mathrm{C}$ for $12 \mathrm{~h}$ or under vacuum in a Centorr Torvac vacuum furnace at $1500^{\circ} \mathrm{C}$ for $5 \mathrm{~h}$. The phase purity of the heat treated pellets was characterized through X-ray diffraction (XRD). The partially reacted samples were subjected to repeated heat treatments with intermittent grinding and consolidation till the formation of phase-pure oxycarbide was achieved. Synthesis of oxycarbide under vacuum called for single or double heat treatments while processing under flowing argon needed at least three heat-treatment cycles.

X-ray diffraction (XRD) data were acquired using a PANalytical Empyrean X-ray diffractometer, using monochromated $\mathrm{CuK} \alpha_{1}$ radiation operated in reflection (Bragg Brentano) mode in the range $2 \theta=10-$ $90^{\circ}$ with a step size of $0.0170^{\circ}$ and a time per step of $0.765 \mathrm{~s}$. The unit cells of the prepared materials were determined by standard least squares techniques. 
Microstructural characterization of titanium oxycarbide specimens was carried out using a scanning electron microscope (SEM, JEOL JSM 6700F) and a transmission electron microscope (TEM, JEOL JEM-2010). SEM characterisation was carried out on the fracture surfaces of titanium oxycarbide specimens. Samples for transmission electron microscopy were prepared by grinding oxycarbide samples in a mortar and pestle in acetone. A pipette was used to place a drop of the oxycarbide particle suspension on a holey carbon film on a $3 \mathrm{~mm}$ copper grid. The density of samples was measured by Micromeritics AccuPyc gas pycnometer using helium.

Solid state nuclear magnetic resonance (nmr) measurements were carried out using a $400 \mathrm{MHz}$ Bruker Avance III Spectrometer equipt with a 7mm MAS HX probe. Data was collected using the DEPTH pulse sequence to supress spins that experience less than $\pi / 4$ pulse length and minimise spurious signal ${ }^{23}$. The $\pi / 2$ pulse was set to $8 \mu \mathrm{s}$ and $\pi$ puslse to $16 \mu \mathrm{s}$. Recyel time was $0.1 \mathrm{~s}$ and $2 \mathrm{k}$ data points were sampled. Thermo-gravimetric analyses of the samples were carried out using a Netzsch STA 449 Jupiter instrument. Samples for oxidation analysis were heated to $1200{ }^{\circ} \mathrm{C}$ at $5{ }^{\circ} \mathrm{C}$ per minute in flowing air.

Magnetic susceptibility measurements were carried out using a Superconducting quantum interference device (SQUID magnetometer)

Contacts for four point conductivity measurements were applied to samples using RS Silver loaded epoxy adhesive. Conductivity measurements were carried out between $70 \mathrm{~K}$ and $250 \mathrm{~K}$ by mounting the samples on an Oxford Instruments cryogenic insert column mounted in a liquid nitrogen dewar. The temperature was controlled using an oxford instruments IT503 temperature controller. The resistance of samples was measured using a Keithley 2401 sourcemeter.

\section{Results and Discussion}

When the solid state synthesis of titanium oxycarbides is carried out at $1400^{\circ} \mathrm{C}$ in flowing argon multiple firings and remilling steps are required to get a phase pure product. XRD traces from each step of this 
process are shown in Figure 1a. Initially the sample consists of cubic fluorite $\mathrm{TiC}$ and monoclinic TiO. After the initial firing of the sample, the XRD pattern shows peaks corresponding to unreacted TiC and broad titanium oxycarbide peaks consistant with the expected cubic rocksalt structure. The position of the TiC peaks remain largely unchanged, indicating limited diffusion of oxygen into the TiC structure. The broadness of the titanium oxycarbide peaks indicate that this phase is compositionally inhomogeneous. After being reground and refired the $2 \theta$ values of the TiC peaks increase slightly indicating a small amount of oxygen diffusion while the intensity of the peaks have reduced relative to the oxycarbide peaks. The oxycarbide peaks have narrowed, indicating increased homogeneity. After the third firing only a small remnant of the TiC peaks remain, while the titanium carbide peaks have become more defined. This slow incorporation of the $\mathrm{TiC}$ into the oxycarbide is due to its refractory nature compared to the $\mathrm{TiO}$. $\mathrm{TiC}$ has a very high melting point and fully occupied octahedral sites, two characteristics that typically lead to slow diffusion. Carbon diffusion into $\mathrm{TiO}$ is more rapid due to its vacancies on both the titanium sites and octahedral sites and its much lower melting point.

Figure $1 \mathrm{~b}$ shows the $\mathrm{XRD}$ traces of $\mathrm{TiO}_{1-\mathrm{x}} \mathrm{C}_{\mathrm{x}}$ fired at $1500-1600{ }^{\circ} \mathrm{C}$ under vacuum. All compositions apart from the starting material $\mathrm{TiO}$ show diffraction patterns consistent with a cubic fluorite structure as expected for full solid solution between $\mathrm{TiO}$ and $\mathrm{TiC}$. Apart from $\mathrm{TiO}$, there are no additional reflections that would indicate ordering of any vacancies or oxygen and carbon on the titanium interstitial sites. However, the similarity of the atomic scattering factors of carbon and oxygen, make it impossible to differentiate between oxygen and carbon sites using XRD. A similar study on titanium carbonitrides was unable to differentiate between carbon and nitrogen by Rietveld refinement. ${ }^{24}$

A plot of cubic lattice parameter with $\mathrm{x}$ is shown in Figure 1c. Across the entire composition range studied, the variation of lattice parameter with composition is non-linear. However, the variation of lattice parameter with composition is linear from $\mathrm{x}=0$ to $\mathrm{x}=0.4$ and from $\mathrm{x}=0.5$ to $\mathrm{x}=1$. When the trend is considered as a whole the variation in lattice paremter suggests a change in solid solution mechanism across the series. The increase in lattice parameter across the solid solution of $3.6 \%$. is unusually large, 
but might be considered consistent with the changing defect contents between the end members Between $\mathrm{x}=0(\mathrm{TiO})$ and $\mathrm{x}=0.5$ the increase in lattice parameter with $\mathrm{x}$ is significantly greater than between $\mathrm{x}=0.5$ and $x=1.0(\mathrm{TiC})$. Between $\mathrm{x}=0$ and $\mathrm{x}=0.5$ the lattice parameter varies from $4.177 \AA$ to $4.2993(10) \AA$, a $2.9 \%$ increase, while between $x=0.5$ and $x=1.0$ the lattice parameter only increases to $4.3253(19) \AA$, a much lower $0.6 \%$ increase. These results are in good agreement with available literature values. ${ }^{20}$

Macrographs of the resulting pellets after firing are shown in Figure 1d. the carbon content of oxycarbide increases, the colour of the sample gradually changes from initial golden color of $\mathrm{TiO}(\mathrm{x}=0)$ to bronze colour for the sample with $\mathrm{x}=0.5$ and finally it changes to dark grey-black for samples with $\mathrm{x}$ values of 0.9 and higher

Back-scattered electron (BSE) micrographs of $\mathrm{TiO}_{0.8} \mathrm{C}_{0.2}(\mathrm{x}=0.2)$ and $\mathrm{TiO}_{0.2} \mathrm{C}_{0.8}(\mathrm{x}=0.8)$ are shown in Figure 1e and 1f respectively. The lower carbon $x=0.2$ sample has lower porosity and a larger grain size than $x=0.8$ sample. The presence of higher porosity and smaller grain size in the microstructure of the oxycarbide sample with $\mathrm{x}=0.8$ is consistent with lower densification associated with the more refractory nature of higher carbon containing samples.

The selected-area electron diffraction patterns recorded from $\mathrm{TiO}_{0.5} \mathrm{C}_{0.5}$ in Figure $2 \mathrm{a}$, $\mathrm{b}$ and c show diffuse scattering not apparent in the x-ray diffraction patterns. Similar diffuse scattering is observed in nonstoichiometric vanadium, titanium and niobium carbides which also have rock salt type structures and is associated with ordering of carbon vacancies on the interstitial sites. ${ }^{25,26}$ It is unlikely that ordering of vacancies in $\mathrm{TiO}_{0.5} \mathrm{C}_{0.5}$ caused by electron beam damage would lead to the diffuse scatter observed in Figure 3 as the opposite effect has been observed in vanadium carbide. When the selected-area diffraction pattern of vanadium carbide, $\mathrm{V}_{6} \mathrm{C}_{5}$, is observed in the TEM the interaction of carbon atoms with the electrons of the TEM causes them to be displaced to vacant interstitial sites, disordering the carbon lattice. This process reduces and eventually removes superlattice reflections and diffuse scattering from the electron diffraction patterns rather than causing them. ${ }^{27}$ An alternative explanation for the diffuse 
scattering may be the segregation or clustering of oxygen and carbon rich regions in the sample. Neutron diffraction studies by Zubkov et al. ${ }^{22}$ on the near-stoichiometric composition $\mathrm{TiO}_{0.57} \mathrm{C}_{0.44}$ and by Tasmetov et $a .^{21}$ on the high-vacancy composition $\mathrm{TiO}_{0.08} \mathrm{C}_{0.545}$ have both reported the formation of ordered structures. Recent studies on the thermodynamics of titanium oxycarbides and stability of titanium oxycarbide thin films have indicated that although there is a large driving force for the formation of titanium oxycarbides at elevated temperatures, they are not thermodynamically stable at low temperatures. ${ }^{12}$ An X-ray photoelectron spectroscopy study by Calvillo et al. on the carbothermal transformation of $\mathrm{TiO}_{2}$ into titanium oxycarbide found that decompostion occurred on cooling resulting in the formation of various titanium oxides and elemental carbon and the possible segregation of $\mathrm{TiO}$ and TiC related phases. ${ }^{28}$

The composition of samples was analysed by Static ${ }^{13} \mathrm{C}$ solid state NMR and TGA. The resulting NMR spectra, shown in Figure 3, consists of broad signals of around $\sim 20 \mathrm{kHz}$ and confirm the presence of carbon in these samples. Signals could only be obtained for samples where fraction of carbon on the interstitial sites exceeded $33 \%$. The chemical shift was measured at the center of gravity of the most intense part of the signal and shows an upfield shift as the carbon content decreases. Furthermore, the introduction of oxygen to the samples is accompanied by a two-fold increase in the line width of the main signal which varies from $9 \mathrm{kHz}-18 \mathrm{kHz}$. This variation in peak shift and linewidth with $\mathrm{x}$ is similar to that observed in the $\operatorname{TiN}_{1-\mathrm{x}} \mathrm{C}_{\mathrm{x}}$ system $^{29}$ where a linear dependency was reported. For $\mathrm{x}=0.4$ there is an increase in resolution evident by a signal at $260 \mathrm{ppm}$ and for $\mathrm{x}=0.5$, a broad signal upfield of the main signal. This could be indicative of the decomposition or segregation in these samples. The spectrum of $x=0.33$ is weak due to dilution of carbon in the sample.

The mass change that accompanies the oxidation of $\mathrm{TiO}_{1-\mathrm{x}} \mathrm{C}_{\mathrm{x}}$ to $\mathrm{TiO}_{2}$ in air was determined by thermogravimetric analysis to confirm that no loss of oxygen or carbon from the samples occurs during the formation reactions:

$\mathrm{TiO}_{1-\mathrm{x}} \mathrm{C}_{\mathrm{x}} \rightarrow \mathrm{TiO}_{1-\mathrm{x}-\alpha} \mathrm{C}_{\mathrm{x}-\alpha}+\alpha \mathrm{CO}(\mathrm{g})$ 
The results of the TGA analysis are listed in Table 1 . All but one of the mass changes are within $1 \%$ of the expected values giving measured compositions close to the nominal targets. The sample with $\mathrm{x}=0.2$ had a measured weight gain that was $1.67 \%$ less than expected giving a composition of $\mathrm{TiO}_{0.76} \mathrm{C}_{0.16}$ instead of $\mathrm{TiO}_{0.8} \mathrm{C}_{0.2}$, according to equation 1 .

The density of the samples was determined by helium pycnometry. These results are plotted in Figure 4a. Both precursors, $\mathrm{TiO}$ and $\mathrm{TiC}$, were found to have their expected literature values, $4.95 \mathrm{~g} \mathrm{~cm}^{-3}$ and $4.93 \mathrm{~g}$ $\mathrm{cm}^{-3}$ respectively. Also, shown in Figure 4a are curves corresponding to the expected densities of the oxycarbides if the titanium and interstitial sites are fully occupied, as in $\mathrm{TiC}$, and if $15 \%$ of the $\mathrm{Ti}$ and $\mathrm{O}$ sites are vacant, as in TiO. It can be seen that most of the measured density values for the titanium oxycarbides synthesised lie intermediate between these two curves, indicating that they have neither the fully occupied rock salt structure of $\mathrm{TiC}$ nor the $15 \%$ vacancies on the titanium and interstitial sites of TiO. The exceptions to this are the $\mathrm{x}=0.1$ and $\mathrm{x}=0.8$ samples, the density of of the sample with $\mathrm{x}=0.1$ falls on the curve corresponding to the $15 \%$ vacancy structure while the sample with $x=0.8$ corresponds to the fully occupied rock salt structure.

When these density results are combined with the lattice parameters obtained by XRD to calculate the occupancies of the unit cell, as shown in Figure 4b, it can be seen that each oxycarbide composition is a step in the gradual transition from the high vacancy content of TiO to the vacancy free structure of the TiC. The largest decrease in vacancy level occurs between $x=0.1$ and $x=0.6$ where the proportion of vacancies to occupied sites decreases from $15 \%$ to $2.5 \%$. This large decrease corresponds to the large decrease in lattice parameter from $x=0.1$ to $x=0.6$ apparent in Figure $1 \mathrm{c}$. The $7.4 \%$ vacancies that was measured for $\mathrm{x}=0.4$ agrees well with the site occupancy reported by Zubkov et al. ${ }^{22}$ for the similar composition $\mathrm{TiO}_{0.44} \mathrm{C}_{0.57}$. The $6.1 \%$ vacancies level measured here for $\mathrm{x}=0.5$ is higher than the $3.7 \%$ reported by Zainulin et al. ${ }^{20}$ for the same composition in the $\mathrm{TiO}_{\mathrm{x}} \mathrm{C}_{0.5}(\mathrm{x}=0-0.8)$ system. In that system the gradual incorporation of oxygen into $\mathrm{TiC}_{0.5}$ does not result in equal number of vacancies on the titanium and interstitial sites, except for $\mathrm{TiO}_{0.5} \mathrm{C}_{0.5}$ where the combined number of carbon and oxygen 
atoms are equal to the number of titanium atoms. Zainulin et al. attributed the formation of vacancies in oxycarbides to the stabilisation of the structure by the screening of titanium-titanium interactions. ${ }^{20}$

The variation in magnetic susceptibility, $\chi_{\mathrm{m}}$, with temperature of selected samples are shown in Figure 5a. The samples were zero field cooled and measured in a 50 Oe magnetic field. All samples were found to be Pauli Paramagnetic and could be fitted by the Curie-Weiss equation:

$\chi_{\mathrm{m}}=\mathrm{A}+\mathrm{BTC} /(\mathrm{T}+\theta)$

where $\mathrm{C}$ is the Curie constant, $\mathrm{T}$ is the absolute temperature and $\theta$ is the Weiss constant. Fitting parameters are shown in Table 2 . The $\mathrm{x}=0.8$ sample has a significantly larger Curie constant than other compositions, which signifies the presence of more paramagnetic defects or impurities. As this seems to be the onset point for significant concentrations of $\mathrm{M}-\mathrm{O}$ defect pairs, this could tally with the presence of short range frustration. There is no evidence of super conductivity for temperatures greater than $5 \mathrm{~K}$ for any of the samples tested.

The variation in resistivity with temperature of a range of samples is shown in Figure $5 \mathrm{~b}$, minimal variation in conductivity with temperature is observed. Such low variation of conductivity with temperature is similar to non-stoichiometric transition metal carbides where conduction electrons are scattered by vacancies. ${ }^{30}$ A previous study by Ivanov et al. has shown that conductivities are reduced at low carbon contents due to the increased level of defects and the greater ionic character of the bonding. ${ }^{13}$ Determination of the variation of conductivity with composition is complicated by the difficulty in obtaining defect-free high density samples from these materials. For compounds where $\mathrm{x}=0.2$ and greater there appears to be a decrease in resistivity as carbon content increases, however the effects of density and microstructure cannot be discounted. 


\section{Conclusions}

XRD confirms that all compositions apart from $\mathrm{TiO}$ in this solid solution series have cubic rocksalt structures (Fm-3m) with no evidence of ordering of oxygen and carbon on the non-metal sites. The nonlinear variation of lattice parameter with composition can be attributed to variations in the level of vacancies on the titanium and non-metal sites and diffuse scattering detected by selected-area electron diffraction in the TEM indicates some evidence of local ordering of vacancies or segregation of carbon and oxygen rich regions. Measurements of conductivity and magnetic susceptibility confirm all compositions are good metallic conductors and due to their robust nature this series offer an importnew set of alternative materials for current collection in a wide range of electrochemical applications.

\section{ACKNOWLEDGMENT}

We acknowledge support from EPSRC for Platform Grant EP/K015540/1 and the Royal Society for Wolfson Merit Award WRMA 2012/R2.

\section{AUTHOR INFORMATION}

\section{Corresponding Author}

John T.S. Irvine, School of Chemistry, University of St Andrews, St Andrews, Fife KY16 9ST, Scotland, UK.

email jtsi@st-and.ac.uk,

\section{Present Addresses}

Abul K. Azad, Faculty of Integrated Technologies, University Brunei, Darussalam, Gadong BE1410. Amit Sinha, Powder Metallurgy Division, Bhabha Atomic Research Centre, Vashi Complex, Navi Mumbai, 400703. India.

Jun Zhou, Department of Electrical Power Engineering, Xi' an Jiatong University, Shaanxi, China

\section{Author Contributions}

The manuscript was written through contributions of all authors. 


\section{REFERENCES}

1. B. Jiang, K. Huang, C. Zhanmin and H. Zhu, Metall. Trans. A, 2012.

2. A. A. Valeeva, A. A. Rempel' and A. I. Gusev, Inorg. Mater, 2001, 37, 603-612.

3. S. Bartowski, M. Neumann, V. Kurmaev, V. V. Fedorenko, S. N. Shamin, M. Cherkashenko, S. N. Nemnonov, A. Winiarski and D. C. Rubie, Phys. Rev. B, 1997, 56, 10656-10667.

4. A. N. Christensen, Acta Chemica Scandinavica, 1990, 44, 851-852.

5. $\quad$ P. G. Wahlbeck and P. W. Gilles, 1966, 49, 180-183.

6. $\quad$ F. J. Morin, Phys. Rev. Lett., 1959, 3, 34-36.

7. J. B. Goodenough, Phys. Rev., 1960, 117, 1442-1451.

8. $\quad$ F. C. Walsh and R. G. A. Wills, Electrochimica Acta, 2010, 55, 6342-6351.

9. M. M. Ottakam Thotiyl, S. A. Freunberger, Z. Peng, Y. Chen, Z. Liu and P. G. Bruce, Nat Mater, 2013, 12, 1050-1056.

10. J. B. Holt and Z. A. Munir, J. Mater. Sci, 1986, 21, 251-259.

11. C. Gao, B. Jiang, Z. Cao, K. Huang and Z. Hongmin, Rare Metals, 2010, 29, 547-551.

12. J. Kim and S. Kang, J. Mater. Chem. A, 2014, 2, 2641-2647.

13. N. A. Ivanov, L. P. Andreeva and P. V. Gel'd, Sov. Powder Metall., 1978, 8, 613-616.

14. R. Hahn, F. Schimdt-Stein, J. Solonen, S. Thiemann, Y. Song, J. Kunze, V.-P. Lehto and P. Schmuki, Angnew. Chem. Int. Ed., 2009, 121.

15. C. Rüdiger, J. Brumbarov, F. Wiesinger, S. Leonardi, O. Paschos, C. Valero-Vidal and J. KunzeLiebhaüser, ChemCatChem, 2013, 5, 3219-3223.

16. J. M. Chappe, A. C. Fernandes, C. Moura, E. Alves, N. P. Barradas, N. Martin, J. P. Espinos and F. Vaz, Surf. Coat. Tech., 2012, 206, 2525-2534.

17. A. C. Fernandes, P. Carvalho, F. Vaz, N. M. G. Parreira, E. Le Bourhis and J.-P. Riviere, Plasma Process. Polm., 2007, 4, S83-S88.

18. A. Ouensanga, J. Less-Common Met., 1979, 63, 225-235.

19. T. Hashinin, T. Yamamoto, M. Ohyanagi and Z. A. Munir, J. Am. Ceram. Soc., 2003, 86, $2067-$ 2073.

20. Y. G. Zainulin, S. I. Alyamovsky and G. P. Shveikin, J Phys. Chem. Solids, 1978, 39, 29-31.

21. M. Y. Tashmetov, V. T. Em, B. N. Savenko and G. Batdemberel, Crystallography Reports, 2003, 48, 106-111.

22. V. G. Zubkov, I. I. Matveenko, L. B. Dubrovskaya, G. D. Bogomolo and P. V. Geld, Doklady Akademii nauk SSSR, 1970, 191, 323-325.

23. D. G. Cory and W. M. Ritchey, J. Magn. Reson., 1988, 80, 128-132.

24. G. Levi, W. D. Kaplan and M. Bamberger, Mater. Lett., 1998, 35, 344-350.

25. J. Billingham, P. S. Bell and M. H. Lewis, Acta Crystallogr. A, 1972, A28, 602-606.

26. M. Sauvage and E. Parthe, Acta Crystallogr. A, 1972, A28, 607-616.

27. J. D. Venables and R. G. Lye, Philos. Mag., 1972, 19, 565-582.

28. L. Calvillo, D. Fittipaldi, C. Rüdiger, M. Favaro, C. Valero-Vidal, C. Di Valentin, A. Vittadini, N. Bozzolo, S. Jacomet, L. Gregoratti, J. Kunze-Liebhaüser, G. Pacchioni and G. Granozzi, J. Phys. Chem. C, 2014, 118, 22601-22610.

29. K. J. D. MacKenzie, R. H. Meinhold, D. G. McGavin, J. A. Ripmeester and I. Moudrakovski, Solid State Nucl. Mag, 1995, 4, 193-201.

30. W. S. Williams, Int. J.Refract. Met. H., 1999, 17. 
a.

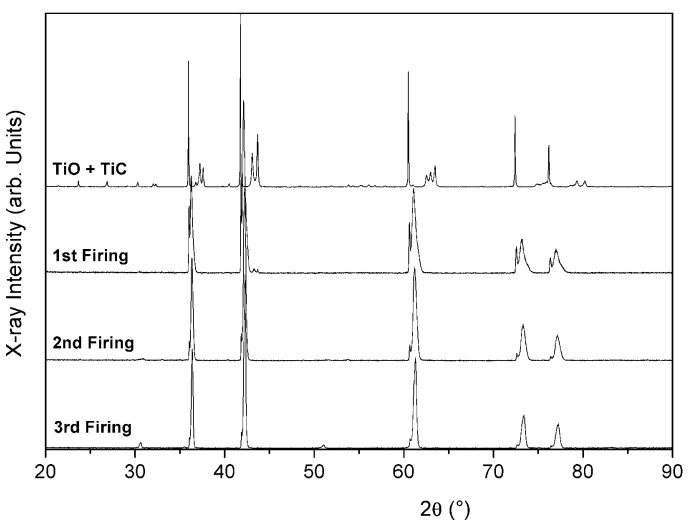

C.

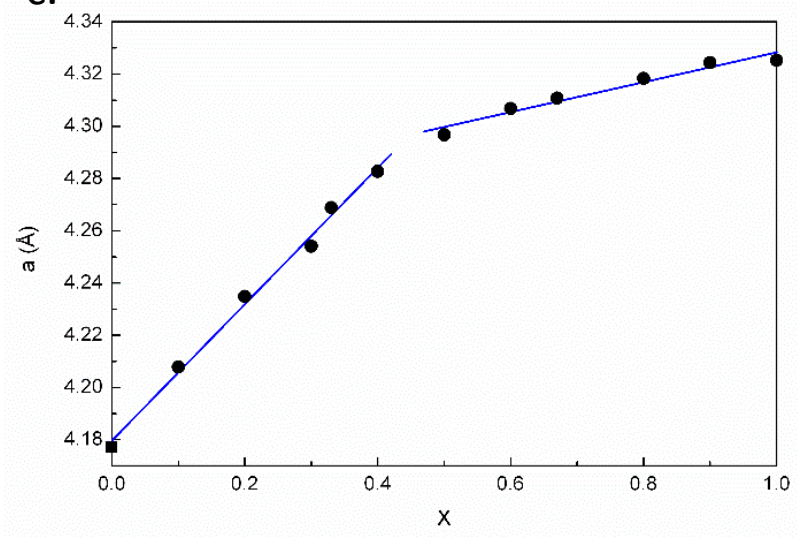

b.

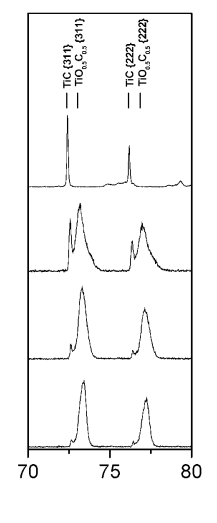

d.


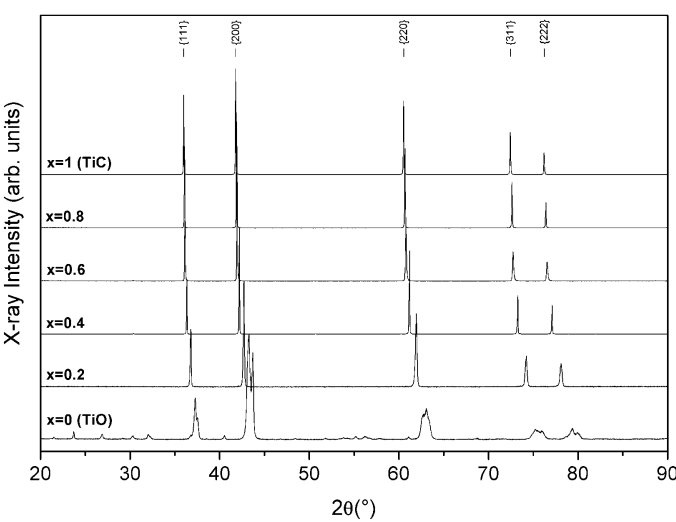

Figure 1. a. The XRD pattern of the $\mathrm{x}=0.5, \mathrm{TiO}_{0.5} \mathrm{C}_{0.5}$ sample prior to and after subsequent firings at 1400 ${ }^{\circ} \mathrm{C}$. b. The XRD patterns of $\mathrm{TiO}_{1-\mathrm{x}} \mathrm{C}_{\mathrm{x}}$ where $\mathrm{x}=0,0.2,0.4,0.6,0.8$ and 1.0 , c. the corresponding variation in cubic lattice parameter with $\mathrm{x}$, the lattice parameter value for cubic $\mathrm{TiO}$ was taken from Christensen, ${ }^{4}$ d. corresponding macrographs of each sample and back-scattered electron micrographs of e. the $\mathrm{x}=0.2$ and $\mathrm{f}$. $\mathrm{x}=0.8$ samples.

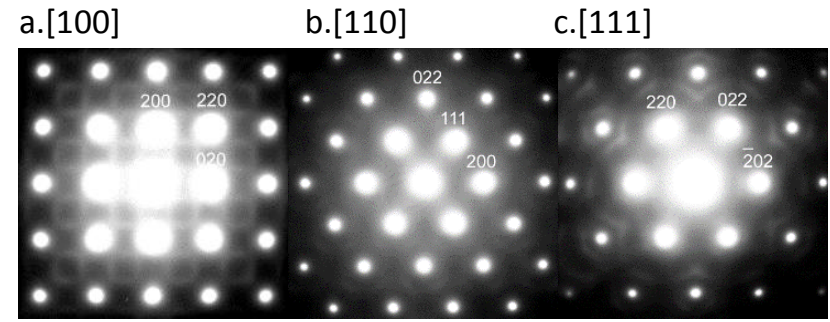

Figure 2. Selected area electron Diffraction pattern of $\mathrm{TiO}_{0.5} \mathrm{C}_{0.5}$ orientated parallel to the a. [100], b. [110] and c. [111] zone axes. 


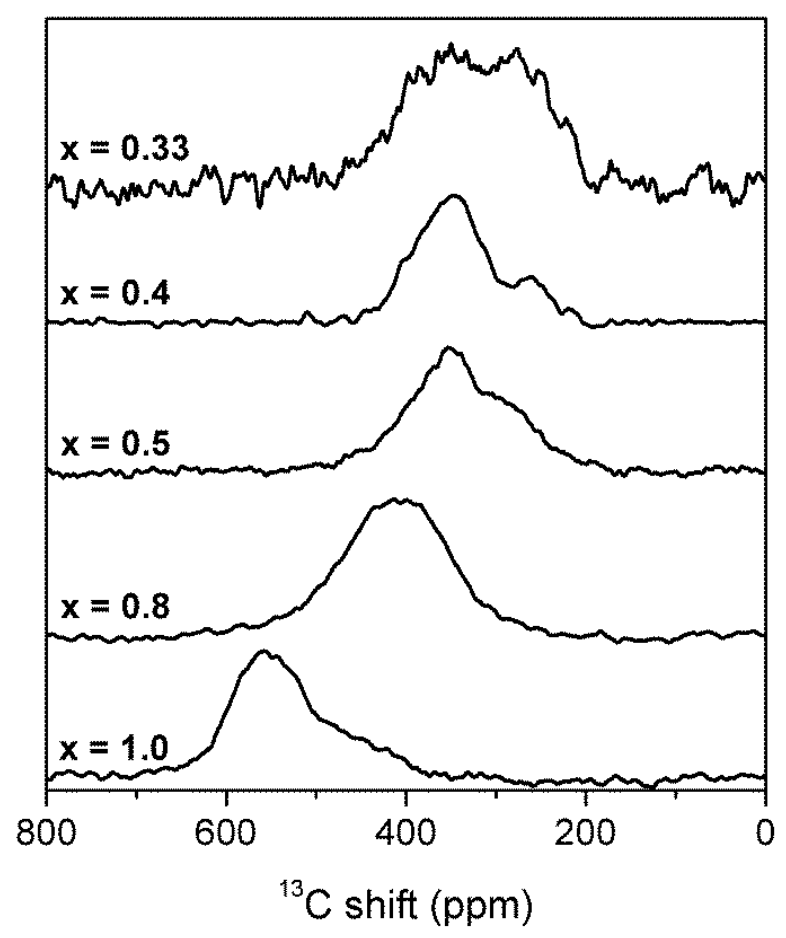

Figure 3. Static ${ }^{13} \mathrm{C}$ Solid state nuclear magnetic resonance results for selected samples.
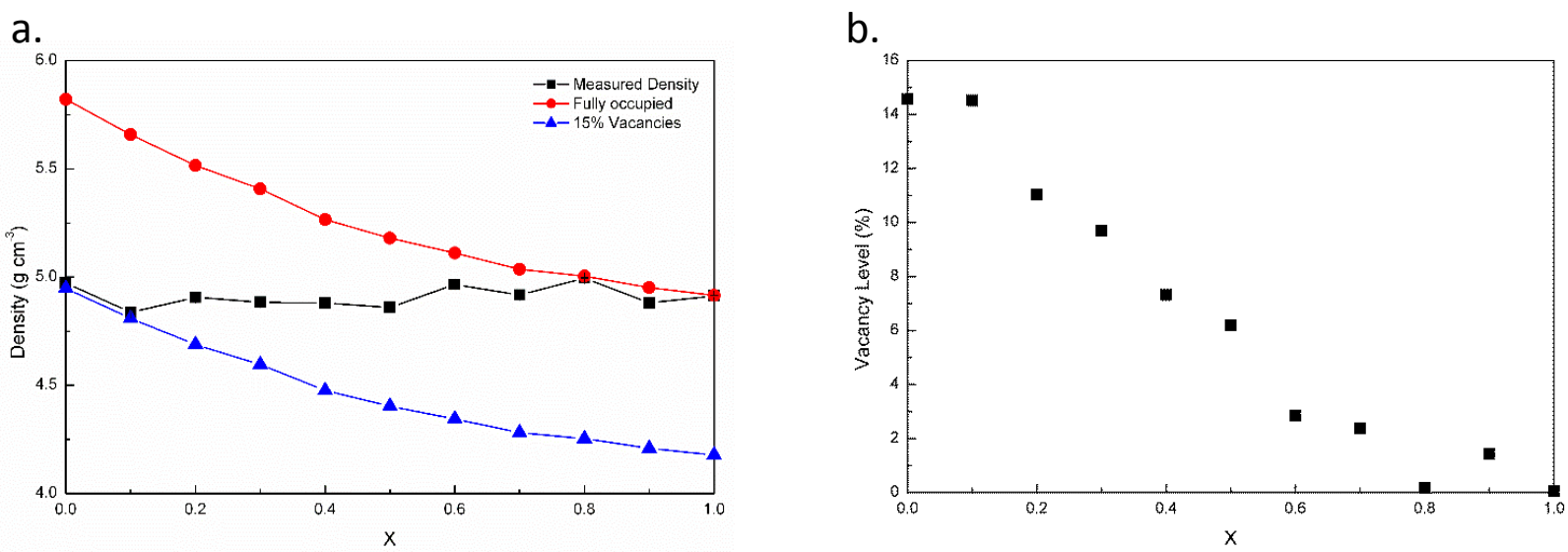

Figure 4. a. The variation of density as measured by helium pycnometry compared to densities predicted by assuming full occupancy of the unit cell, as in $\mathrm{TiC}$, and $15 \%$ vacancies as in $\mathrm{TiO}$. b. The variation in the level of vacancies on titanium and non metal sites with $\mathrm{x}$ as calculated from helium pycnometry and $\mathrm{XRD}$ results. 
a.

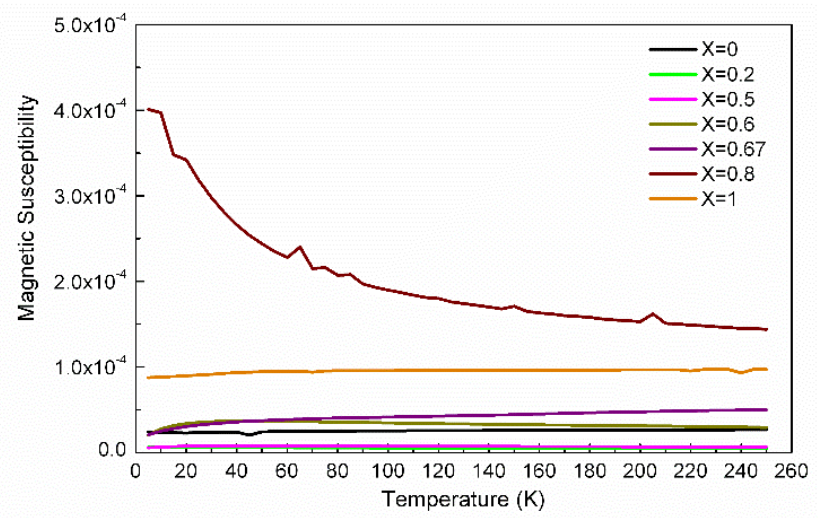

b.

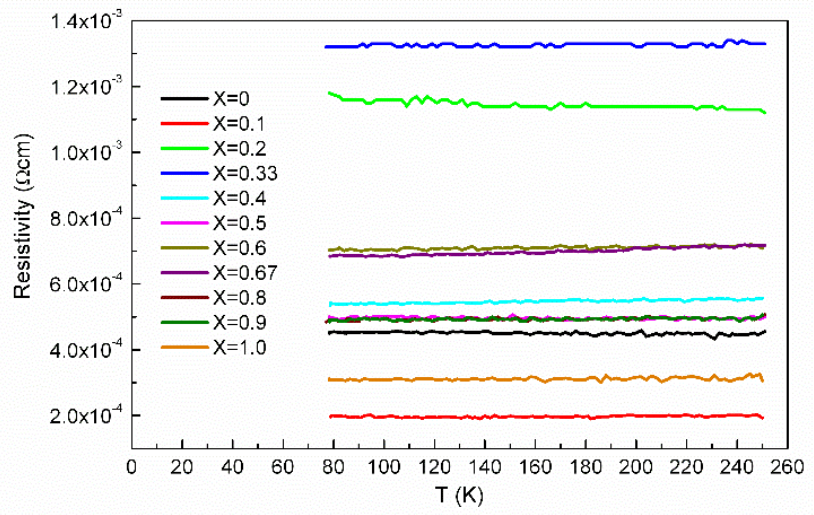

Figure 5. Variation of a. magnetic susceptibility and b. resistivity with temperature for $\mathrm{TiO}_{1-\mathrm{x}} \mathrm{C}_{\mathrm{x}}$.

Table 1. TGA results of titanium oxycarbide samples under flowing air

\begin{tabular}{cccccc}
\hline & \multicolumn{2}{c}{ Composition } & \multicolumn{3}{c}{ Mass Change [\%] } \\
X & Target & Measured & Expected & Measured & Difference \\
\hline 0 & $\mathrm{TiO}$ & $\mathrm{TiO}_{1.00}$ & 125.05 & 124.99 & -0.05 \\
0.1 & $\mathrm{TiO}_{0.9} \mathrm{C}_{0.1}$ & $\mathrm{TiO}_{0.88} \mathrm{C}_{0.084}$ & 125.84 & 124.96 & -0.7 \\
0.2 & $\mathrm{TiO}_{0.8} \mathrm{C}_{0.2}$ & $\mathrm{TiO}_{0.76} \mathrm{C}_{0.16}$ & 126.63 & 124.51 & -1.67 \\
0.3 & $\mathrm{TiO}_{0.7} \mathrm{C}_{0.3}$ & $\mathrm{TiO}_{0.68} \mathrm{C}_{0.28}$ & 127.44 & 126.52 & -0.72 \\
0.4 & $\mathrm{TiO}_{0.6} \mathrm{C}_{0.4}$ & $\mathrm{TiO}_{0.59} \mathrm{C}_{0.39}$ & 128.25 & 127.75 & -0.39 \\
0.5 & $\mathrm{TiO}_{0.5} \mathrm{C}_{0.5}$ & $\mathrm{TiO}_{0.49} \mathrm{C}_{0.49}$ & 129.08 & 128.64 & -0.34 \\
0.6 & $\mathrm{TiO}_{0.4} \mathrm{C}_{0.6}$ & $\mathrm{TiO}_{0.40} \mathrm{C}_{0.60}$ & 129.92 & 129.93 & 0.01 \\
0.7 & $\mathrm{TiO}_{0.3} \mathrm{C}_{0.7}$ & $\mathrm{TiO}_{0.31} \mathrm{C}_{0.71}$ & 130.77 & 131.63 & 0.66 \\
0.8 & $\mathrm{TiO}_{0.2} \mathrm{C}_{0.8}$ & $\mathrm{TiO}_{0.21} \mathrm{C}_{0.81}$ & 131.63 & 132.51 & 0.67 \\
0.9 & $\mathrm{TiO}_{0.1} \mathrm{C}_{0.9}$ & $\mathrm{TiO}_{0.11} \mathrm{C}_{0.91}$ & 132.50 & 133.08 & 0.44 \\
1 & $\mathrm{TiC}$ & $\mathrm{TiC}_{1.00}$ & 133.38 & 133.36 & -0.01 \\
\hline
\end{tabular}

Table 2. Magnetic susceptibility fitting parameters

\begin{tabular}{ccccc}
\hline $\mathrm{X}$ & $\mathrm{A}\left[\mathrm{m}^{3} \mathrm{~mol}^{-1}\right]$ & $\mathrm{B}\left[\mathrm{m}^{3} \mathrm{~K}^{-1} \mathrm{~mol}^{-1}\right]$ & $\mathrm{C}\left[\mathrm{m}^{3} \mathrm{Kmol}^{-1}\right]$ & $\theta[\mathrm{K}]$ \\
\hline 0 & 0.00003 & $5.34 \mathrm{E}-09$ & $-1.60 \mathrm{E}-04$ & -37.55 \\
0.2 & $5.42 \mathrm{E}-06$ & $-5.91 \mathrm{E}-09$ & 0.00005 & -36.07 \\
0.5 & $8.47 \mathrm{E}-06$ & $-7.95 \mathrm{E}-09$ & -0.00002 & -2.22 \\
0.6 & $4.00 \mathrm{E}-05$ & $-4.60 \mathrm{E}-08$ & -0.00013 & 1.19 \\
0.67 & 0.00004 & $4.58 \mathrm{E}-08$ & -0.00031 & -11.11 \\
0.8 & $6.0 \mathrm{E}-5$ & $1.01 \mathrm{E}-07$ & 0.017 & -43.67 \\
1 & $1.0 \mathrm{E}-4$ & $-1.25 \mathrm{E}-08$ & -0.00064 & -38.82 \\
\hline
\end{tabular}

